\title{
Optimum design of SRC composite beams
}

\author{
Shan-Suo Zheng ${ }^{1, \text { a }}$, Lei Zeng ${ }^{1}$, Wei-Hong Zhang ${ }^{2}$, Jie Zheng ${ }^{1}$, Lei Li ${ }^{1}$ and Bin Wang ${ }^{1}$ \\ 1 School of Civil Engineering, Xi'an University of Architecture and Technology, Xi'an 710055, P.R. China \\ 2 Northwestern Polytechnical University, Xi'an 710049, P.R. China
}

Received 2 July 2007, accepted 4 February 2008

\begin{abstract}
Based on experimental study of bond-slip behaviours between steel shape and concrete, an optimal design scheme of single objective and discrete variables is proposed to design steel reinforced concrete (SRC) frame beams. In the optimum scheme, design variables include the layout dimensions of SRC frame structure, structural member sections, strength of concrete and steel, dimensions of steel shapes. The objective function is cost of the entire materials applied to construct SRC frame structure. The constraint conditions are main requirements stated in Chinese code for design of SRC structures, basic design rules, reasonable calculating theories and indispensable constructions, as well as some mature and consistent conclusions confirmed by experimental studies on calculating methods of SRC structures based on the bond-slip theory between steel shape and concrete. These may be a reference in analyzing and designing SRC frame structures and provide a practical method satisfying civil engineering practice and requirements stated in the codes.
\end{abstract}

Key words: SRC beam; bond-slip theory; optimum design; mixing penalty function method

\section{Introduction}

Steel reinforced concrete composite structure, SRC structure for short, is a main kind of steel and concrete composite structure that steel shapes are embedded in the reinforced concrete [1]. SRC Structure has been applied in many practical engineering, such as high-rise buildings, heavy-duty factory buildings, long-span bridges, submarine tunnels, drilling platforms, etc.

SRC structural members have a relatively small sectional dimension and a high bearing capacity. SRC structures obtain a better integral stiffness, and possess an excellent seismic behaviour. The fine bond behaviour between steel shape and concrete is the base of their cooperation. The cooperation is the reflection of the advantages of SRC structures. The bond behaviour directly affects the bearing capacity, failure modalities, crack, deformation and calculating methods etc [2].

Most of the researches on SRC structures at home and abroad focused on approximate calculation of member's strength, stiffness etc, but few of them take the bond-slip behaviour between steel shape and concrete into account in analyzing member's ultimate bearing capacity. Nowadays, test and research on SRC structures indicate that bond-slip phenomenon exists between steel shape and concrete, and this bond-slip behaviour has a significant impact on mechanical behaviour, failure form and calculation hypothesis of structural members, especially after

\footnotetext{
${ }^{a}$ Corresponding author: zhengshansuo@263.net
}

arriving $80 \%$ of ultimate bearing capacity, the influence is more apparent.

Optimum design converts structural analysis from the traditional and passive method to an active optimum design method, which solves optimal problems under certain preset conditions by applying computer and greatly improves economic benefit and design efficiency [3,4]. Optimum design of SRC structures is a design method that acquires maximum economic value at minimal cost. Few researchers study on optimum design of SRC structures at home and abroad, so a perfect optimization design system of the structures has not been formed. Based on experimental study of bond-slip behaviours between steel shape and concrete, an optimal design scheme of single objective and discrete variables is proposed to design SRC frame beams in this paper.

\section{Calculation of SRC frame beams based on bond-slip theory}

\subsection{Theoretical frame}

In SRC structural members, there exists bonding action between the two different materials of steel and concrete, which enables stress to transfer effectively each other on the interface of steel and concrete and furnishes working stress needed to fulfill loading capacity of structures in steel and concrete [5]. Bond stress is a kind of shear force in macroscopical view. Experiments indicate that 


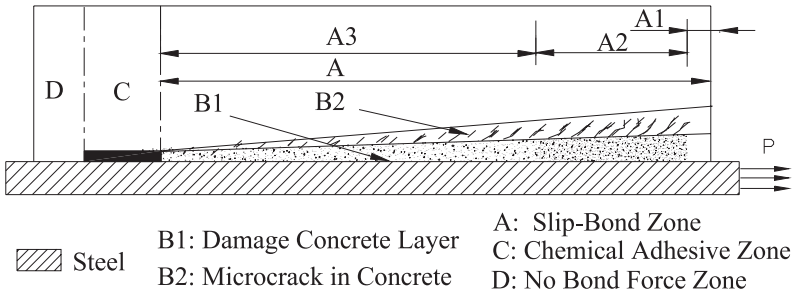

Fig. 1. Distribution of interfacial bond stress.

the distribution of bond stress on the interface of steel and concrete is illustrated as Figure 1.

Based on theory of mechanics of materials, the distribution of bond stress along steel surface is given as follows

$$
\tau(x)=\frac{A_{s}}{u} \frac{d \sigma_{x}}{d x}=\frac{A_{s}}{u} E_{s} \frac{d \varepsilon_{x}}{d x}=\frac{-k_{1} A_{s} \varepsilon_{\max }}{u} E_{s} e^{-k_{1} x}
$$

where $E_{s}$ is elastic modulus of steel; $d \sigma_{x} / d x, d \varepsilon_{x} / d x$ are steel cross-section normal stress and normal strain increment along anchorage length respectively; $\sigma_{x}, A_{s}$ and $u$, for full section, are average stress, area and perimeter of steel section respectively, for flange or web, are average stress, area, perimeter of flange or web section respectively.

The distribution of slip between the interface of steel and concrete is given as follows

$$
s(x)=s_{\max } e^{-k_{2} x}
$$

where $s(x)$ is the slip quantity at different part of crosssection along anchorage length; $s_{\max }$ is the maximum slip quantity along anchorage length; $k_{2}$ is characteristic exponent of slip distribution.

\subsection{Failure criteria of bond-slip}

According to the difference of use requirements to the SRC structures, the failure criterion is different. In the special working conditions, the composite action of encased steel and concrete must be fully required, and even the local bond slippage at the loading end is forbidden [6]. This state is defined as local bond-slip failure. General SRC structures should meet the requirements of the normal use state and ultimate bearing capacity state, which requires that the bond-slip failure along the whole embedment should not take place. The state is defined as complete bond-slip failure.

Criterion I to the failure of local bond-slip

$$
T_{1}=F_{1}\left(\tau, \sigma_{z}\right) / P_{0}-1
$$

Criterion II to the failure of complete bond-slip

$$
T_{2}=F_{2}\left(\tau, \sigma_{z}\right) / P_{u}-1
$$

where $P_{0}$ is local bond-bearing capacity at the loading end; $P_{u}$ is ultimate bond-bearing capacity along the

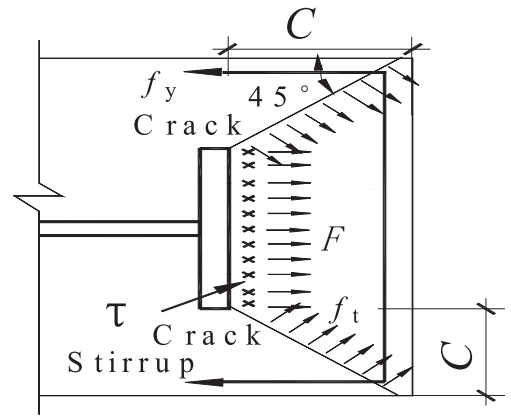

Fig. 2. Computation sketches for $Q_{u}$.

embedment; $F_{1}\left(\tau, \sigma_{z}\right)$ and $F_{2}\left(\tau, \sigma_{z}\right)$ are resultant forces of $\tau$ and $\sigma_{z}$.

$$
\begin{aligned}
P_{0}= & C_{a} l_{0} \tau_{0}^{\prime}, \quad \tau_{0}^{\prime}=0.364 f_{t}+0.1991 l_{a} / h_{a}+1.5209 \rho_{s v} \\
& +0.4998 C_{a} / h_{a}-0.3027 \\
P_{u}= & 4 b_{f} l_{a} \tau_{u}, \quad \tau_{u}=0.004 f_{t}+0.0874 \rho_{s v}+0.8624 C_{a} / h_{a} \\
& -0.0454 l_{a} / h_{a}+0.9107
\end{aligned}
$$

where $f_{t}$ is axial tensile strength; $l_{a}$ is embedment length; $\rho_{s v}$ is traverse stirrup ratio; $C_{a}$ and $h_{a}$ are respectively perimeter and height of traverse section of steel shape; $l_{0}$ is the diffusion length of chemical bond force which is approximately equal to the height of traverse section of steel shape; $\tau_{0}^{\prime}$ is the average bond stress on the whole steel shape surface within the diffusion length $l_{0} ; \tau_{u}$ is the average bond stress on the steel flange surface within the embedment length $l_{a}$, which neglects the bond action between web and concrete.

Providing the complete bond-slip failure is known with respect to Criterion II, the failure model of bond-slip can be obtained uniquely with Criterion III to traverse crack in concrete, which is given as follows

$$
T_{3}=G\left(\sigma_{r}, \sigma_{\theta}\right) / Q_{u}-1
$$

where $G\left(\sigma_{r}, \sigma_{\theta}\right)$ is resultant force of $\sigma_{r}$ and $\sigma_{\theta} ; Q_{u}$ is ultimate load-bearing capacity of traverse crack- resistance, which is greatly influenced by the confinement of concrete encasement and stirrups, and it can be deduced exactly when concrete cover thickness and stirrups ratio are relatively large.

There is an assumption: the tension stress in the concrete cover reaches $f_{t}$ and the tension stress in stirrup reaches $f_{y}$ after the full crack of transverse concrete. The computation sketches are shown in Figure 2. Then

$$
Q_{u}=2 C f_{t}+2 A_{s} f_{y} / s
$$

where $C$ is the concrete cover thickness, mm; $f_{y}$ is the yield strength of stirrup, $\mathrm{N} / \mathrm{mm}^{2} ; s$ is the space of stirrups, $\mathrm{mm} ; A_{s}$ is the cross-sectional area of stirrups, $\mathrm{mm}^{2}$. The failure models in the SRC structure are shown in Table 1.

\subsection{Constitutive relationship of bond-slip}

According to the present experimental data [7], it is generally accepted that the bond stress is commonly evaluated 
Table 1. Failure criteria of bond-slip.

\begin{tabular}{|c|c|}
\hline Failure criteria & Results of bond-slip failure \\
\hline$T_{1}<0$ & Steel shape cooperates with concrete entirely \\
\hline$T_{1} \geqslant 0$ & Local bond-slip failure \\
\hline & Splitting failure of concrete \\
\hline$T_{2} \geqslant 0$ & $T_{3}<0 \quad$ Embedment failure of steel shape \\
\hline$T_{2}<0$ & Yield failure of steel shape \\
\hline
\end{tabular}

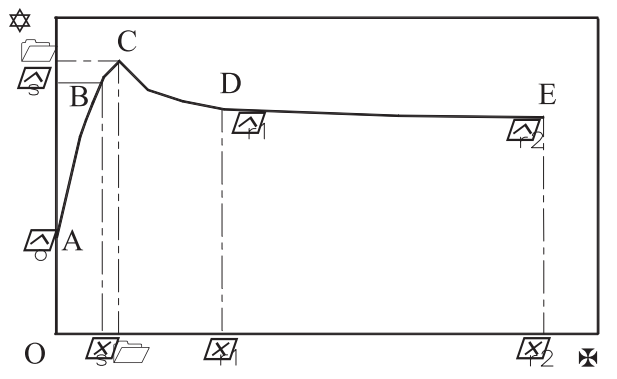

Fig. 3. Standard $\tau-S$ curve.

as the average bond stress, which is the load transferred between the flange of steel shape and concrete encasement, divided by the total surface area of the flange within concrete, in which the bond stress on surface of the web is neglected. Based on the statistic analyses of the force and slip relationship, a typical bond-slippage $(\tau-S)$ curve is obtained, as is shown in Figure 3. The $\tau-S$ curve includes ascending stage and descending stage. The ascending stage includes no slip (OA), linearly ascending ( $\mathrm{AB})$, and nonlinearly ascending (BC) parts. The descending stage includes sharply descending and smooth parts. The typical bond-slippage curve can be standardized as follows: $x=S / S_{u}$ and $y=\tau / \tau_{u}$, where $S_{u}$ is the slippage at the loading end in the ultimate bond-bearing capacity state. The characteristics of the standard curve are as follows:

a. Starting point: $x=0, y=y_{0}>0$. Specimens have virtually no slip for loads up to $40 \% P_{u}$, and local chemical adhesive force between encased steel and concrete at the loading end equals the applied load. The composite action of encased steel and concrete is fully developed.

b. Ascending stage: $0 \leqslant x \leqslant 1, \frac{d^{2} y}{d x^{2}}>0, \frac{d y}{d x} \geqslant 0$, $x=1, y=1$. When the relative slippage occurs, the applied load equals the friction and mechanical interlock forces within the slip zone and chemical adhesive force within the bond zone. Slip increases linearly with increasing of load before the control point $\left(P_{s}\right.$, $\left.S_{s}\right)$, where $P_{s}$ is about $70 \% P_{u}$. After $P_{s}$, the standard curve tends to ascend nonlinearly.

c. Descending stage: $1 \leqslant x, \frac{d^{2} y}{d x^{2}}<0, \frac{d y}{d x}<0, y_{x \rightarrow \infty}=y_{r}$. After $P_{u}$, the increase of the friction and interlock forces is smaller than the fall of adhesive force. After the load descends to $70-80 \% P_{u}$, cracks in concrete are steady. The part of the curve is nearly horizontal.
The ascending stage and descending stage of the standard $\tau-S$ curve can be fitted with mathematical expressions respectively

$$
x \leqslant 1 \quad y=a x^{2}+b x+c \quad x \geqslant 1 \quad y=\frac{x}{m x+n} .
$$

The parameters in the equation (9) can also be specified with the control points of $\left(0, y_{0}\right),\left(x_{s}, y_{s}\right),(1,1)$ and $\left(x_{r}, y_{r}\right)$ acquired in the test, as follows

$$
\begin{gathered}
a=\frac{y_{0}+x_{s}-y_{s}-y_{0} x_{s}}{x_{s}-x_{s}^{2}}, \quad b=\frac{y_{0}+x_{s}^{2}-y_{s}-y_{0} x_{s}^{2}}{x_{s}-x_{s}^{2}} \\
c=y_{0}, \quad m=\frac{x_{r}-x_{r} y_{r}}{y_{r}-x_{r} y_{r}}, \quad n=\frac{x_{r}-y_{r}}{x_{r} y_{r}-y_{r}}
\end{gathered}
$$

The values of control points in the standard $\tau-S$ curve can directly be obtained by test or from the regressive formulas of control points. The $\tau-S$ curves obtained in the test and ones fitted with mathematical expressions agree well with each other.

With the positional difference of the embedment, the $\tau-S$ curves are different $[8,9]$. The $\tau-S$ curves in the different location can be obtained in test. The characteristics of the $\tau-S$ curves are as follows: With the increase of the embedment length, the threshold bond strength, the maximum bond stress and local slippage decrease. Near the loading end, the $\tau-S$ curves include ascending stage and descending stage; near the free end, the curves only include a descending stage. The residual bond stress and slippage are in steady state for all the $\tau-S$ curves. The $\tau-S$ curves of the loading end are similar to that of different location. It is assumed that there are constant ratios between the values of control points in the $\tau-S$ curves, then the below simplified equations can be obtained

$$
\begin{aligned}
& \frac{\tau_{0}(x)}{\bar{\tau}_{0}}=\frac{\tau_{s}(x)}{\bar{\tau}_{s}}=\frac{\tau_{u}(x)}{\bar{\tau}_{u}}=A(x), \quad \frac{\tau_{r}(x)}{\bar{\tau}_{r}}=1, \\
& \frac{S_{s}(x)}{\bar{S}_{s}}=\frac{S_{u}(x)}{\bar{S}_{u}}=B(x), \quad \frac{S_{r}(x)}{\bar{S}_{r}}=1 .
\end{aligned}
$$

All the $\tau-S$ curves of the different embedment length can be specified by the standard $\tau-S$ curve and position functions of $A(x)$ and $B(x)$, which can be deduced from the experimental results. With respect to the separation between the steel and concrete at the loading end, $\tau(0)$ is zero.

$$
\begin{aligned}
A(x)= & -384.52 x^{6}+1256.1 x^{5}-1604.6 x^{4} \\
& +1011 x^{3}-322.04 x^{2}+44.276 x \\
B(x)= & 671 x^{2}-1.6373 x+1.0
\end{aligned}
$$




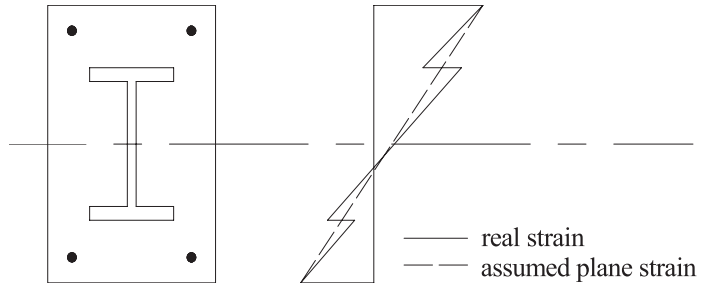

Fig. 4. Section strain diagram of SRC.

where $x=X / l_{a}, X$ is the distance from the anchorage point to the loading end. $A(x)$ and $B(x)$ do not indicates the characteristics of the other three parameters, and the researcher will follow up them particularly.

Due to obvious slipping zones on the interface of steel and concrete, the bearing capacity of solid-web steel reinforced concrete beams is lower and is reduced to some extent. As a result of the impact of bond-slip, SRC beam's section strain is clearly not in accordance with the assumption of plane section, a strain mutant occurs at the top and bottom steel flange, as shown in Figure 4. To assure that the depth of compression zone and the limit of bearing capacity remain unchanged, a modified plane section will be used to replace the multi-line cross-section strain. While calculating bearing capacity of solid-web steel reinforced concrete beams, the following assumptions were made to take into account the influence of bond-slip cracks.

a. Cross-section strain should conform to the assumption of modified plane section.

b. When damaged, the ultimate compression strain of concrete at edge of compression zone is 0.003 .

c. At ultimate state, compressive stress can be described as rectangle distribution, where $f_{c m}=f_{c}$, depth of compression zone is $0.8 x_{0}, x_{0}$ is actual depth of compression zone.

d. At ultimate state, the concrete can not bear any pulling tension in tensile area.

\section{Optimal calculating model}

\subsection{Design variables}

The design scheme of SCR frame beams may be determined by length of beam $(l)$, strengths of concrete, steel, longitudinal reinforcement and stirrup $\left(f_{c}, f_{a}, f_{y}, f_{y v}\right)$, dimensions of cross-section (depth $h$, width $b$ ), cross-section dimensions of steel (bottom flange width $b_{a f}$, bottom flange thickness $t_{a f}$, top flange width $b_{a f}^{\prime}$, top flange thickness $t_{a f}^{\prime}$, web depth $h_{w}$, web thickness $t_{w}$ ), the distance from bottom (top) flange to tension (compression) zone edge, which is just the thickness of covering layer $\left(a_{a}\right.$, $\left.a_{a}^{\prime}\right)$, diameter and quantity of longitudinal reinforcement at bottom $\left(d_{s}, n_{s}\right)$, diameter and quantity of longitudinal reinforcement at top $\left(d_{s}^{\prime}, n_{s}^{\prime}\right)$, the distance from tensile (compression) reinforcement to compression (tension) zone edge $\left(a_{s}, a_{s}^{\prime}\right)$, diameter and range interval of stirrup $\left(d_{s v}, s_{s v}\right)$, length coverage and range interval of added stirrup $\left(l_{s v}, s_{1}\right)$, anchorage length of steel $\left(l_{a}\right)$.

\subsection{Objective function}

Objective function of SCR frame beams is total cost per unit length, as construction and labor costs for different design change not large and can be considered as an invariable value, so they are not considered in the objective function. The cost of engineering materials is composed of four parts: concrete cost, steel cost, longitudinal reinforcement cost, and stirrup cost. The expression of objective function is given as follows

$$
\begin{aligned}
\operatorname{Cost}(X)= & \operatorname{CostC}(X)+\operatorname{Cost} \mathrm{A}(X) \\
& +\operatorname{CostS}(X)+\operatorname{CostSV}(X)
\end{aligned}
$$

where $\operatorname{CostC}(X), \operatorname{Cost} \mathrm{A}(X), \operatorname{CostS}(X), \operatorname{CostSV}(X)$ are concrete cost, steel cost, longitudinal reinforcement cost, and stirrup cost respectively.

\subsection{Constraint conditions}

\subsubsection{Bearing capacity requirements}

According to the computational theory of SRC frame beams based on the bond-slip theory mentioned above, bearing capacity constraint conditions were given as follows $[10]$

a. Bending carrying capacity requirements

$$
\begin{aligned}
M \leqslant & \frac{1}{\gamma_{\mathrm{RE}}}\left[f_{c} b x\left(h_{0}-x / 2\right)+f_{y}^{\prime} A_{s}^{\prime}\left(h_{0}-a_{s}^{\prime}\right)\right. \\
& \left.+f_{a}^{\prime} A_{a f}^{\prime}\left(h_{0}-a_{a}^{\prime}\right)+M_{a w}\right]
\end{aligned}
$$

$$
f_{c} b x+f_{y}^{\prime} A_{s}^{\prime}+f_{a}^{\prime} A_{a f}^{\prime}-f_{y} A_{s}-f_{a} A_{a f}+N_{a w}=0 .
$$

b. Shear carrying capacity requirements

$$
\begin{gathered}
V \leqslant \frac{1}{\gamma_{\mathrm{RE}}}\left[0.06 f_{c} b h_{0}+0.8 f_{y v} \frac{A_{s v}}{s} h_{0}+0.58 f_{a} t_{w} h_{w}\right] \\
V_{b} \leqslant 0.36 f_{c} b h_{0} \\
\frac{f_{a} t_{w} h_{w}}{f_{c} b h_{0}} \geqslant 0.10
\end{gathered}
$$

\subsubsection{Bearing capacity requirements}

a. Requirements on height, width and ratio of height and width of beam

$$
b \geqslant 300 \mathrm{~mm}, \quad h>300 \mathrm{~mm}, \quad h \leqslant 4 b .
$$


b. Dimension requirements of steel and panel.

Requirements on thickness of covering layer:

$$
\begin{gathered}
b_{a f} \leqslant b-200, b_{a f}^{\prime} \leqslant b-200 \\
b_{a f}^{\prime} \leqslant 2 b / 3, \quad b_{a f}>0, \quad b_{a f}^{\prime}>0, h_{w}>0 .
\end{gathered}
$$

Requirements on steel welding and constructional details:

$$
t_{a f} \geqslant 6 \mathrm{~mm}, \quad t_{a f}^{\prime} \geqslant 6 \mathrm{~mm}, \quad t_{w} \geqslant 6 \mathrm{~mm} .
$$

c. Constructional detail requirements on longitudinal reinforcement.

Requirements on diameter:

$16 \mathrm{~mm} \leqslant d_{s} \leqslant 50 \mathrm{~mm} ; 16 \mathrm{~mm} \leqslant d_{s}^{\prime} \leqslant 50 \mathrm{~mm}$

Requirements on clear spacing:

$$
\begin{aligned}
& \frac{h-50-n_{s} d_{s}}{n_{s}-1} \geqslant \operatorname{MAX}\left(1.5 d_{s}, 30\right) \\
& \frac{h-50-n_{s}^{\prime} d_{s}^{\prime}}{n_{s}^{\prime}-1} \geqslant \operatorname{MAX}\left(1.5 d_{s}^{\prime}, 30\right) .
\end{aligned}
$$

Requirements on number of longitudinal reinforcements:

$$
n_{s} \geqslant 2, \quad n_{s}^{\prime} \geqslant 2 \text {. }
$$

Requirements on longitudinal reinforcement ratio:

$$
\frac{n_{s} p d_{s}^{2}}{4 b\left(h-a_{s}\right)}>0.003 .
$$

d. Constructional detail requirements on stirrup.

Requirements on diameter:

$$
d_{s v} \geqslant 6+2 \min \left[1, \operatorname{int}\left(\frac{h}{800}\right)\right]
$$

$$
\begin{aligned}
d_{s v} \geqslant 0.25 d_{s}^{\prime} \max \{\min [1, & \left.\operatorname{int}\left(\frac{n_{s}^{\prime}}{3.0}\right)\right], \\
& \left.\min \left[1, \operatorname{int}\left(\frac{d_{s}^{\prime}}{18.0}\right)\right]\right\} .
\end{aligned}
$$

Requirements on range interval of stirrups:

$$
\begin{aligned}
& S_{s v} \leqslant \frac{15 d_{s}^{\prime}}{\left\{\max \left[\min \left(1, \frac{n_{s}^{\prime}}{6}\right), \min \left(1, \frac{d_{s}^{\prime}}{18.0}\right)\right]\right\}^{3}} \\
&-5 d_{s}^{\prime} \min \left[1, \operatorname{int}\left(\frac{n_{s}^{\prime}}{6}\right)\right] \min \left[1, \operatorname{int}\left(\frac{d_{s}^{\prime}}{20}\right)\right] \quad(30) \\
& S_{s v} \leqslant \min \left[1, \operatorname{int}\left(\frac{0.999 \cdot V}{0.07 f_{c} b h_{0}}\right)\right] \\
& \times 50\left\{4+\min \left[1, \operatorname{int}\left(\frac{h}{525}\right)\right]+\min \left[1, \operatorname{int}\left(\frac{h}{825}\right)\right]\right\} \\
& \quad+\operatorname{int}\left[\frac{\min \left(V, 0.07 f_{c} b h_{0}\right)+1}{V+1}\right] 300 .
\end{aligned}
$$

$$
S_{s v}>100
$$

Requirements on the stirrup ratio:

$$
A_{s v} / b S_{s v} \geqslant 0.24 f_{t} / f_{y v} .
$$

e. Requirements on thickness of covering layer

$$
a_{a}-0.5 t_{a f} \geqslant 100 \mathrm{~mm}
$$

\subsubsection{Deformation restrictions}

SRC beams satisfying the above conditions can generally meet the deformation requirements of design code, so crack and deflection restrictions will not be regarded as constrained condition, which will work as a final check for the design [11].

\subsubsection{Constraint conditions of discrete variables}

All of the 15 variables of SRC frame beam optimization design are discrete variables except top and bottom steel flange width, web depth and steel covering depth, and discrete variables are defined by specification of materials and sectional dimensions commonly used in engineering.

\section{Mixing penalty function method of discrete variables}

The Optimum design of SRC composite beams can be solved by using sequential unconstrained minimization technique (SUMT for short), which is an indirect method translating constraint optimization into an unconfined one. The following is its primary principles $[12,13]$.

The mathematic model of constraint optimization is written as

$$
\begin{array}{ll}
\min & \boldsymbol{f}(\boldsymbol{X}) \quad \boldsymbol{X} \in \boldsymbol{R}^{n} \\
\text { s.t. } & \boldsymbol{g}_{i}(\boldsymbol{X}) \leqslant 0(i=1,2 \ldots, p) \\
& \boldsymbol{h}_{j}(\boldsymbol{X})=0(j=1,2 \ldots, p)
\end{array}
$$

where $\boldsymbol{X}=\left[x_{1}, x_{2}, \ldots, x_{n}\right]^{T}$ is decision-making vector; $\boldsymbol{f}(\boldsymbol{x})$ is objective function vector; $\boldsymbol{g}_{i}(\boldsymbol{X}) \leqslant 0, \boldsymbol{h}_{j}(\boldsymbol{X})=0$ is constraint functions.

Adding $\boldsymbol{g}(\boldsymbol{X})$ and $\boldsymbol{h}(\boldsymbol{X})$ to $\boldsymbol{f}(\boldsymbol{x})$, the original optimization question is translated into an equivalent unconfined one shown as

$$
\begin{aligned}
\min & \boldsymbol{F}\left(\boldsymbol{X}, r_{k}, t_{k}\right) \quad \boldsymbol{X} \in \boldsymbol{R}^{n} \\
& \boldsymbol{X}=\left[x_{1} x_{2} \ldots x_{n}\right]^{T} \\
& k=0,1,2, \ldots
\end{aligned}
$$

$\boldsymbol{F}\left(\boldsymbol{X}, r_{k}, t_{k}\right)$ is an artificial objective function, named as penalty function, and it is expressed as

$$
\begin{aligned}
\min \boldsymbol{F}\left(\boldsymbol{X}, r_{k}, t_{k}\right)= & \boldsymbol{f}(\boldsymbol{X})+r_{k} \sum_{i=1}^{p} \boldsymbol{G}\left[\boldsymbol{g}_{i}(\boldsymbol{X})\right] \\
& +t_{k} \sum_{j=1}^{q} \boldsymbol{H}\left[\boldsymbol{h}_{\boldsymbol{j}}(\boldsymbol{X})\right]
\end{aligned}
$$


where $\boldsymbol{G}\left[\boldsymbol{g}_{i}(\boldsymbol{X})\right], \boldsymbol{H}\left[\boldsymbol{h}_{j}(\boldsymbol{X})\right]$ are fonctionelles of $\boldsymbol{g}_{i}(\boldsymbol{X})$ and $\boldsymbol{h}_{j}(\boldsymbol{X})$ respectively, a group of inequality constraint conditions and equality constraint conditions in regard to the original optimization question; $r_{k}$ and $t_{k}$ are called penalty factors or penalty parameters, which are adjusted according to increase of $k ; \sum_{i=1}^{p} \boldsymbol{G}\left[\boldsymbol{g}_{i}(\boldsymbol{X})\right], \sum_{j=1}^{q} \boldsymbol{H}\left[\boldsymbol{h}_{j}(\boldsymbol{X})\right]$ are called penalty items, and they are non-negative.

It is visible that value of $\boldsymbol{F}\left(\boldsymbol{X}, r_{k}, t_{k}\right)$ is usually larger than value of the original objective function $f(x)$. In order to astringe penalty function $\boldsymbol{F}\left(\boldsymbol{X}, r_{k}, t_{k}\right)$ to the constraint optimum solution $\boldsymbol{x}^{*}$ of original question, the penalty must own the following character

$$
\left.\begin{array}{r}
\lim _{k \rightarrow \infty} r_{k} \sum_{i=1}^{p} \boldsymbol{G}\left[\boldsymbol{g}_{i}(\boldsymbol{X})\right]=0 \\
\lim _{k \rightarrow \infty} t_{k} \sum_{j=1}^{q} \boldsymbol{H}\left[\boldsymbol{h}_{j}(\boldsymbol{X})\right]=0
\end{array}\right\}
$$

which means penalty effect on penalty function will disappear gradually along with continuous adjustment of penalty factors, i.e.

$$
\lim _{k \rightarrow \infty}\left|\boldsymbol{F}\left(X, r_{k}, t_{k}\right)-\boldsymbol{f}(\boldsymbol{X})\right|=0 .
$$

If objective function and constraint function are both continuous and differentiable, it is necessary to satisfy the following equation in gaining extreme point of penalty function, which is K-T condition for constraint extreme point.

$$
\begin{aligned}
\nabla \boldsymbol{F}\left(\boldsymbol{X}, r_{k}, t_{k}\right)= & \nabla \boldsymbol{f}(\boldsymbol{X})+r_{k} \sum_{i=1}^{p} \nabla \boldsymbol{G}\left[\boldsymbol{g}_{i}(\boldsymbol{X})\right] \\
& +t_{k} \sum_{j=1}^{q} \nabla \boldsymbol{H}\left[\boldsymbol{h}_{j}(\boldsymbol{X})\right]=0
\end{aligned}
$$

Optimum question with both equality and inequality constraints can be solved by combining inner point method and outer point method, which is mixing penalty function method.

When constraint conditions are $\boldsymbol{g}_{i}(\boldsymbol{X}) \leqslant 0$ and $\boldsymbol{h}_{j}(\boldsymbol{X})=0$, the general expression of penalty function is as follows:

$$
\begin{aligned}
\boldsymbol{F}\left(\boldsymbol{X}, r_{k}\right)= & \boldsymbol{f}(\boldsymbol{X})-r_{k} \sum_{i \in I_{1}} \frac{1}{\boldsymbol{g}_{i}(\boldsymbol{X})} \\
& +t_{k} \sum_{i \in I_{2}}\left\{\max \left[0, g_{i}(\boldsymbol{X})\right]\right\}^{2}+t_{k} \sum_{j=1}^{q}\left[\boldsymbol{h}_{j}(\boldsymbol{X})\right]^{2}
\end{aligned}
$$

$$
\begin{cases}I_{1}=\left\{i \mid \boldsymbol{g}_{i}\left(\boldsymbol{X}^{(0)}\right)<0\right. & (i=1,2, \ldots, p)\} \\ I_{2}=\left\{i \mid \boldsymbol{g}_{i}\left(\boldsymbol{X}^{(0)}\right) \geqslant 0\right. & (i=1,2, \ldots, p)\}\end{cases}
$$

where $r_{k}$ is a decreasing sequence of positive real number; $t_{k}$ is an increasing sequence of positive real number, $\boldsymbol{X}^{(0)}$ is initial point; $I_{1}, I_{2}$ are two constraint sets.
In the optimization of practical structural engineering, parts even all of the design variables are often discrete variables, which can only take special and discrete values. This means will add several equation constraint conditions to mathematical model, so it can be solved by using mixing penalty function method.

On the assumption that the number of discrete variables is $l$ in design variables, and the rest are continuous variables, in which discrete variables are given as $\boldsymbol{X}^{d}=\left[x_{1}, x_{2}, \ldots, x_{l}\right]^{T}$, then penalty function can be expressed as

$$
\begin{aligned}
\boldsymbol{F}\left(\boldsymbol{X}, r_{k}, t_{k}, s_{k}\right)= & \boldsymbol{f}(\boldsymbol{x})-r_{k} \boldsymbol{G}_{1}\left[\boldsymbol{g}_{i}(\boldsymbol{X})\right] \\
& +t_{k} \boldsymbol{H}\left[\boldsymbol{h}_{j}(\boldsymbol{X})\right]+s_{k} \boldsymbol{D}\left(x_{u}\right)
\end{aligned}
$$

where $r_{k}$ and $t_{k}$ are the same as formula (42). On the right side of equation, the first item is original objective function; the second is punitive item of interior point method considering the constraint condition of $\boldsymbol{g}_{i}(\boldsymbol{X}) \leqslant 0$; the third is punitive item of outside point method considering the constraint condition of $\boldsymbol{h}_{j}(\boldsymbol{X}) \leqslant 0$; the fourth is punitive item to assure specified discrete value for the design variables, $s_{k}$ is penalty factor, which is an increasing sequence of positive real number.

The items in penalty function are as follows

$$
\begin{gathered}
\boldsymbol{G}_{1}\left[\boldsymbol{g}_{i}(\boldsymbol{X})\right]=\sum_{i \in I_{1}} \frac{1}{\boldsymbol{g}_{i}(\boldsymbol{X})} \\
\boldsymbol{H}\left[\boldsymbol{h}_{j}(\boldsymbol{X})\right]=\sum_{j=1}^{q}\left[\boldsymbol{h}_{j}(\boldsymbol{X})\right]^{2} \\
D\left(x_{u}\right)=\sum_{u=1}^{l}\left[\prod_{v=1}^{m_{u}}\left(\frac{x_{u}-z_{u v}}{\bar{x}_{u}-z_{u v}}\right)\right]^{2} \\
\boldsymbol{D}_{u}\left(x_{u}\right)=\left[\prod_{v=1}^{m_{u}}\left(x_{u}-z_{u v}\right)\right]^{2}
\end{gathered}
$$

where $z_{u v}\left(v=1 \sim m_{u}\right)$ is discrete value of variable $x_{u}$; $m_{u}$ is the discrete value number of variable $x_{u} ; \bar{x}_{u}$ is the average value of $z_{u v}$ and $z_{u, v+1}$, i.e. $\bar{x}_{u}=\frac{1}{2}\left(z_{u v}+z_{u, v+1}\right)$.

\section{An example of calculation}

A SRC frame beam bears uniform load and its shear span ratio equals zero. The maximum internal force at beam end section is given as $M_{A}=-500 \mathrm{kNm}$ and $V_{A}=250 \mathrm{KN}$; the maximum bending moment in the middle section of the span equals $300 \mathrm{kNm}$. The calculation diagram is shown in Figure 5. The problem is to choose beam section dimensions, reinforcement consumption and steel consumption to make total cost lowest.

The known conditions are as followings: concrete strength grade is C30; steel grade is Q235; HPB235 is used for longitudinal reinforcement and stirrup; the price of concrete is 500 yuan per cubic meter; the price of steel is 3700 yuan per ton, the price of longitudinal reinforcement 




Fig. 5. Simplified computing sketch of SRC beam.

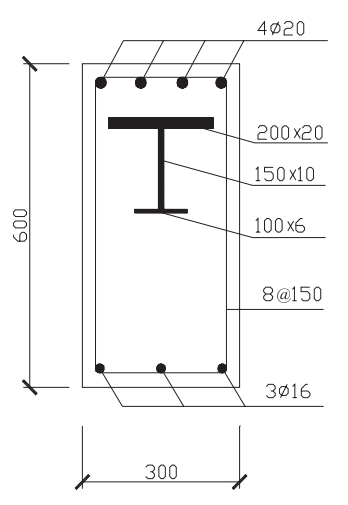

Section A

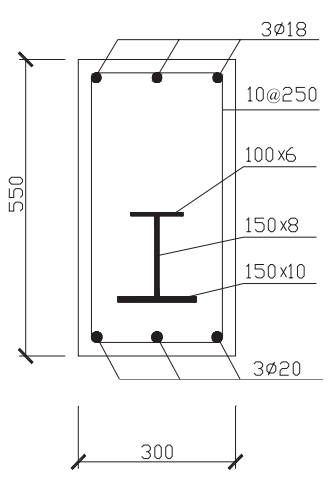

Section C
Fig. 6. Optimized section of SRC beam.

is 3000 yuan per ton, the price of stirrup is 2700 yuan per ton.

The program first checks up initial values. If the values do not satisfy all constraint conditions, the preset initial values will be considered ineffective, and then the initial values satisfied will be generated stochastically. This example is carried out two computations. First time, the initial values cannot satisfy all constraint conditions, so the program produces automatically new initial values, and second time the initial values satisfy all constraint conditions, then the procedure make the optimized computation directly.

Optimum results indicated that the cost of beam end section converges to 318.3 Yuan from the initial 552.4 Yuan, and the cost of middle section of the span converges to 226.4 Yuan from the initial 348.6 Yuan. The final sections are shown in Figure 6.

\section{Conclusion}

This paper uses a discrete variable mixing penalty function optimization algorithm to design SRC frame beams, which is one of mathematical programming methods. The method has extremely strict logic and is suitable for the SRC frame design.

As some of the parameters impact the convergence process in optimum scheme, for different initial condition the convergence process varies obviously, and sometimes the process will be longtime. To improve versatility and stability of the method, it is needed to do more systematic analysis research on the entire optimum process and its parameters.

The authors would like to thank National Natural Science Foundation of China and the Educational Office of Shaan'xi Province in China for their support throughout this research.

\section{References}

1. JSJ138-2001, Technical specification for steel reinforced concrete composite structures, China Architecture and Building Press, Beijing (2002)

2. Zhao Hongtie, Steel and concrete composite structure, Science Press, Beijing (2001)

3. S. Pezeshk, C.V. Camp, D. Chen, Design of nonlinear framed structures using genetic optimization. J. Struct. Engrg. 126, 382-388 (2000)

4. H. Huang, R.W. Xia, Two-level multipoint constraint approximation concept for structural optimization. Structural Optimization 9, 38-45 (1995)

5. J.O. Bryson, R.G. Mathey, Surface condition effect on bond strength of steel beams in concrete. J. ACI 59, 397-406 (1962)

6. M. Keuser, G. Mehlhorn, Finite element models for bond problems. J. Struct. Engrg. 113, 2160-2173 (1987)

7. S.S. Zheng, G.Z. Deng, Y. Yang, M.H. Yu, Experimental study on bond-slip performance between steel shape and concrete in SRC structures. Engineering Mechanics 20, 63-69 (2003)

8. C.W. Roeder, R. Chmielowski, C.B. Brown, Shear connector requirements for embedment steel sections. J. Struct. Engrg. 125, 142-151 (1999)

9. R. Furlong, Binding and Bonding to Composite Columns, Composite and mixed construction. ASCE, 227-253, 330$336(1984)$

10. Zhou Qijing, Jiang Weishan, Pan Taihua, Manual for design and construction of composite structures, China Architecture and Building Press, Beijing (1991)

11. N.M. Hawkins, Strength of concrete encased steel beams. Civil Engineering Transaction of Institution of Australia Engineer E15 (1/2), 39-46 (1973)

12. Charles V. Camp, Shahram Pezeshk, Håkan Hansson, Flexural design of reinforced concrete frames using a genetic algorithm. J. Struct. Engrg. 129, 105-115 (2003)

13. C.K. Choi, N.T. Cheng, Integrated genetic algorithms for optimization of space structures. J. Aerosp. Eng. 6, 3015-328 (1993) 